IRA-International Journal of Technology \& Engineering ISSN 2455-4480

Proceedings of the

International Conference on Science \& Engineering

for Sustainable Development (2017)

Pg. no. 385-393

Published by: Institute of Research Advances https://research-advances.org/index.php/IRAJTE

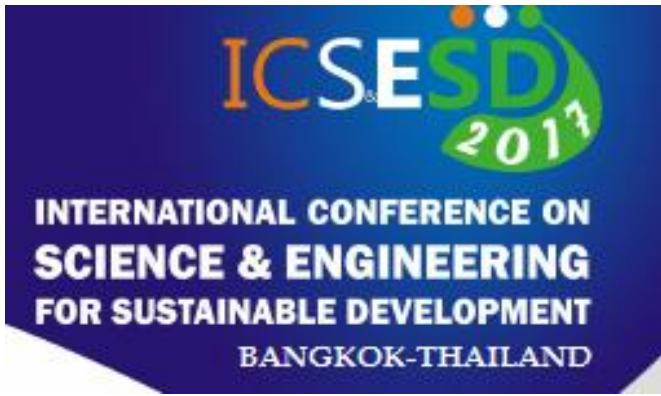

\title{
Disaster Management in Industry: Ergonomic Perspective
}

\author{
R.N.Panchal ${ }^{1}$, A.D.Awasare ${ }^{2}$, J.R.Panchal ${ }^{3}$, V.M.Jamadar ${ }^{4}$, G.V.Shinde ${ }^{5}$, \\ H.M.Kumbhar ${ }^{6}$, A.M.Zende ${ }^{7}$ \\ ${ }^{1}$ Professor and Head, Mechanical Engineering Department, AGTI's DACOE Karad \\ ${ }^{2,4,5}$ Assistant Professor, Mechanical Engineering Department, AGTI's DACOE Karad \\ ${ }^{3}$ Professor, Electronic and Telecommunication Engineering Department, AGTI's DACOE Karad \\ ${ }^{6}$ Vice Principal, AGTI's DACOE Karad. \\ ${ }^{7}$ Professor and Head, Civil Engineering Department, AGTI's DACOE Karad.
}

Type of Review: Peer Reviewed under the responsibility of the Scientific Committee of the Conference and The Institution of Engineers (India).

DOI: http://dx.doi.org/10.21013/ite.ICSESD201737

\section{How to cite this paper:}

Panchal, R.N., Awasare, A.D., Panchal, J.R., Jamadar, V.M., Shinde, G.V., Kumbhar, H.M., Zende, A.M. (2017). Disaster Management in Industry: Ergonomic Perspective. Proceedings of the International Conference on Science \& Engineering for Sustainable Development (2017), 373384. doi:http://dx.doi.org/10.21013/jte.ICSESD201737

(C) International Conference on Science \& Engineering for Sustainable Development \& The Institution of Engineers (India).

\section{(cc) EY-NC}

This work is licensed under a Creative Commons Attribution-Non Commercial 4.0 International License subject to proper citation to the publication source of the work.

Disclaimer: The conference papers as published by the Institute of Research Advances (IRA) are the views and opinions of their respective authors and are not the views or opinions of the IRA. The IRA disclaims of any harm or loss caused due to the published content to any party. 


\begin{abstract}
Plant layout is related with the arrangement of machines, equipment, storage vessels, materials, workplace and warehouse. It is need to the design constraints arising from safety for humans, environment conditions, construction, maintenance, and operation of product with financial balance. Human comfort is very important because it is directly affect on human efficiency. Chemical accidents and spills can be hazardous to peoples, wildlife, and create environmental issues. The good way to reduce the harm caused by chemical accidents is to design and development of layout and plants with good safety controls that operate at lower temperature. The basic aim of paper is to create awareness and safety taring amongst operators working in the plant.
\end{abstract}

Keywords: Plant layout, Workplace, Safety control, environment conditions.

\title{
Introduction
}

The term Disaster Management is organization, planning and application of measures preparing for, responding to and, initial recovery from disasters [2]. One of the worst industrial chemical disasters occurred without warning early on the morning of December 3, 1984, at Union Carbide's pesticide plant in Bhopal, India. While most people slept, a leak, caused by a series of mechanical and human failures, released a cloud of lethal methyl isocyanate over the sleeping city. Some two thousand people died immediately and another eight thousand died later. Health officials, not informed about chemicals at the factory, were completely unprepared for the tragedy. Congressional hearings that followed the Bhopal accident revealed that U.S. companies routinely discharged hazardous chemicals into the air, while emergency planners knew little about the potential for disaster at local industrial facilities. Less than one year later, a Union Carbide plant that produced methyl isocyanate in various Institutes, West Virginia, leaked a toxic gas in the Kanawha Valley. While the West Virginia incident was not another tragedy, it was a shocking reminder that an accident such as the one that occurred at Bhopal could happen in the United States of America. To help emergency service responders know what they are dealing with, the Department of Transportation (DOT) has established a hazardous materials system. Rail cars and trucks carrying toxic materials must display a diamond-shaped of sign having on it a material identification number (MIN), which can be looked up to determine what hazardous and dangerous materials are on board, and a hazard class number and symbol of identification that gives whether the contents are flammable, explosive, corrosive, hazardous etc. Colour codes also convey instant information: blue (health), red (flammability), yellow (reactivity), and white (special notice).

The placard system is as follows:

Hazard class 1: Explosives material

Hazard class 2: Gases (non-flammable, flammable, toxic gas, oxygen, inhalation hazard)

Hazard class 3: Flammable liquids

Hazard class 4: Flammable solids (flammable solid, spontaneously combustible, dangerous when wet)

Hazard class 5: Oxidizer and organic peroxide

Hazard class 6: Toxic/poisonous and infectious substances labels (PG III, inhalation hazard, poison, toxic)

Hazard class 7: Radioactive (I, II, III, and fissile)

Hazard class 8: Corrosive

Hazard class 9: Miscellaneous dangerous goods one of the most common concerns over chemical accidents and hazardous materials spills is acute, or short-term, toxicity.

Toxic contaminants, such as cyanide and chlorine released from hazardous materials spills, pose an immediate threat or cause to people health. For example, a chemical accident in which chlorine gas or cyanide gas is released from tank would likely result in widespread hazardous or toxic cloud, moved through a large number of people were present. Another class of toxicity is chronic or long term. One of the most common types of chronic toxicity is exposure of carcinogens that may cause in cancer twenty to thirty years after the time of the spill. An example of such an exposure occurred on July 10, 1976, in Meda, Italy, a small village about 13 miles north of Milan, where an explosion occurred at 
the ICMESA chemical plant in a 2,4,5-trichlorophenol reactor. (2,4,5-Trichlorophenol is an industrial chemical used as a building block to make pesticides and antiseptics.) A toxic cloud which was containing dioxins, which are very potent cancer-causing chemicals, was released into the atmosphere and spread across the nearby densely populated city of seveso. Exposure to such carcinogens does not result in short-term health problems of people, but also the effects may be expressed decades later [5].

\section{Ergonomics perspective}

\section{What is ergonomics?}

Ergonomics design comes from two Greek words ERGOS (work) and NOMOS (natural law). Loosely translated, it means the rules of work in the plant. Essentially, ergonomics is the science of designing the job to fit the operator, rather than physically forcing the worker's body to fit the work. Many people think that ergonomics is only associated with computer technology However, ergonomic principles can be applied to any task that use your body to work, from doing your household chores to the daily routines of your job work. Ergonomics is used to reduce the wear and tear on the body as well as mind that may cause a task to become difficult or not interested. Ergonomically designed work processes, tools, machines and workstations are adapted to the capabilities and limitations of the human beings. When ergonomic principles are applied in an area of workplace, they improve efficiency, productivity, quality, increase job satisfaction and reduce the risk of fatigue, short-term pain and chronic illnesses, such as job-related musculoskeletal disorders [7].

\section{Ergonomic job design}

Job that is ergonomically designed includes these important elements:

- Variety task - alternating job/ tasks within a job minimizes repetitive activities and reduces wear on the body

- Appropriate work pace - when the pace of work is too fast, the body has very little recovery time between repetitive or forceful movements

- Work breaks - resting, or changing position between tasks helps prevent muscle fatigue and injury

- Rest breaks - stopping work for a period of time during the day provides required physical and mental break

- Training and education -the appropriate job skills to do a job safely and prevents accidents and injury [5]. The Mitigation Phase seeks to prevent hazardous events when possible, reduce their severity when they actually do occur, and minimise the man, machine losses and damages [1].

\section{Ergonomic basics}

Many ergonomic are low-tech and common sense - simple changes can make a big difference. Here are some parameters to help you improve the ergonomics of your workplace area:

- Keep tools, materials, machines in easy reach

- Work at require height in relation to your body - use adjustable equipments (chairs, tables, platforms)

- Work in a best, comfortable posture

- Reduce more repetition in tasks and activities

- Avoid more forceful movements - e.g. striking computer keys with too much force, twisting or jerking to lift very heavy loads.

- Minimise fatigue by taking appropriate work and rest breaks.

- Avoid direct pressure on shoulder, feet and forums.

- Maintain a comfortable environment (heat, light, humidity) [5].

\section{Ergonomic Layout Design}

Different housekeeping activities are often used first in adopting the continuous improvement way of life. Here adopted some practice at job place are use $5 \mathrm{~S}$ : Sort out what is unneeded; Set-In-Order what must be kept; Shine everything that remains and establish a cleaning schedule; Standardize the 
system throughout the facility and provide employees with training Sustain the effort with selfdiscipline and resources and time to improve their job place. In assembly line, control of ergonomic risks at operators workplaces is a necessary by legislation, care for health of operators and economic considerations[8]. Methods for estimating ergonomic risks of workplaces are integrated into production routines at most firms that use the assembly-type of production.

\section{Methodology}

- Form a company Leader (Preferably Manager of respective area / Zone) and Team Members (Group of $4 \sim 5$ people) for every Zone. Ensure the involvement of all members.

- Form a committee of managers (Preferably Department Heads) who should take a decision for the disposal of unwanted materials / Scrap, out from the factory. Fix a date and time for Red Tag Zone Campaign \& carry out the audit across all Zones.

- Find \& Identify unwanted materials and tie it with a RED TAG.

- Other than product scrap, Red Tagged items should be moved to respective RED TAG Zone, as shown in Fig.1.1.

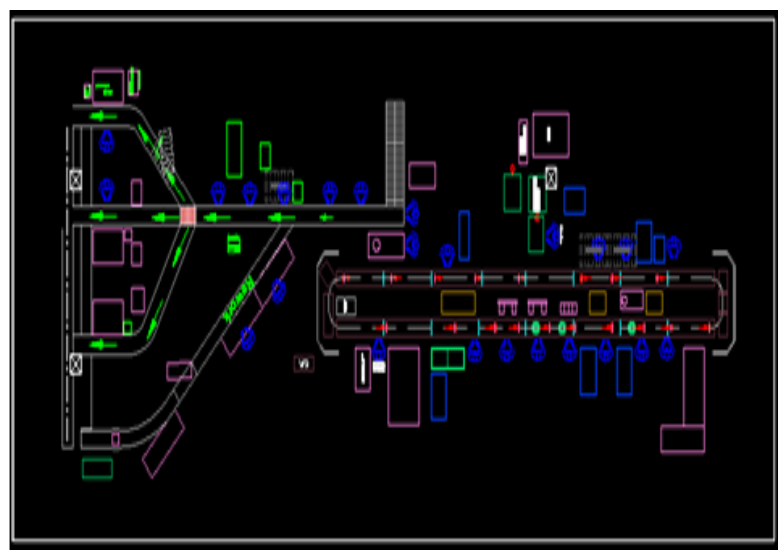

Fig.1.1 Ergonomic Layout Design

\section{Safety essentials}

\section{Look at the big picture}

- Recognize that accidents hurt everyone. An accidental injury can have far-reaching effects, not only on you, but also on your family, co-workers and employer.

- Take responsibility for keeping your home, workplace and recreational areas as safe and risk-free as possible.

\section{Follow the Golden Rule}

- When you're at work, at home or out having fun, act as safely around others as you would want them to act around you.

- Recognize and report or repair safety hazards.

- Before you take unsafe "short cuts," remember that this could be the time that you cause an accident.

3. Know the common hazards

- Be aware of the four main causes of accidents: o physical overload - lifting too much, straining, twisting or making the body move in unnatural ways o unexpected impact - being hit by or hitting an object o slips and falls - falling from a height or falling during a slip o machine accidents - getting caught in moving machine parts. 
4. Put your mind to safety

- Accidents don't just happen. They are always caused by a combination of: o unsafe attitudes coming to work angry, not taking safety rules seriously, not paying attention to the task at hand o unsafe behaviours - failing to follow safety procedures, fooling around, refusing to wear protective clothing o unsafe conditions.

\section{Protect your back}

- Stretch and strengthen your back. Exercise your back and stomach muscles to protect yourself from injury.

- Use safe lifting techniques to avoid strains and injuries.

\section{Avoid chemical hazards}

- Know how to protect yourself from the health hazards of the chemicals you use.

- Read the warning labels on any chemical before you use it.

- Remember that an unlabelled chemical is a dangerous one.

- Never sniff or smell an unlabelled chemical [7].

\section{Safe Design}

Safe design begins at the concept development phase when choices are made about design, materials used and methods of manufacture. In these early phases there is more chance to design-out hazards or incorporate compatible risk control measures with the original design concept and functional requirements of the product. Safe design applies to every phase in the plant lifecycle, from design to disposal. Operational complexity and the role of human operators in assembly line production are then needed for product variety [7]. This means thinking about potential hazards and design solutions as the plant is manufactured transported, installed, commissioned, used, maintained, repaired, decommissioned, dismantled, disposed of or recycled as shown in Fig.1.2 A \& B.

$\mathbf{A}$

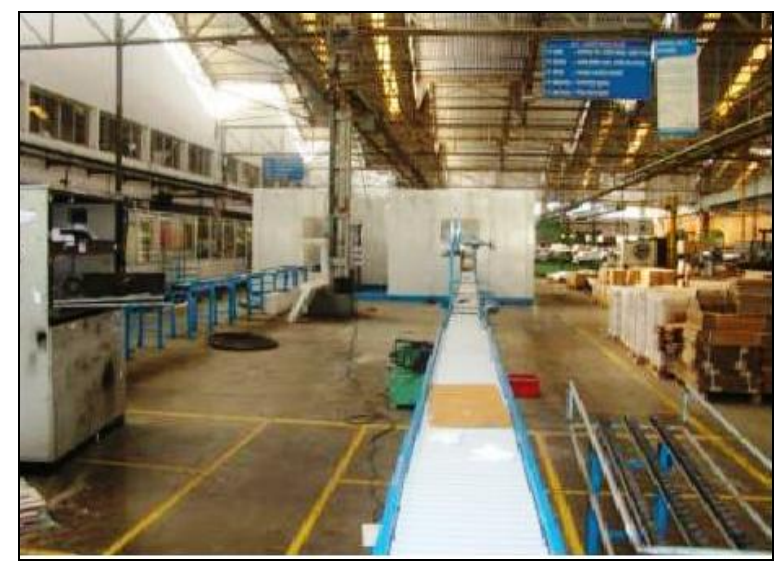

Fig.1.2 Safety Layout with mapping 
B

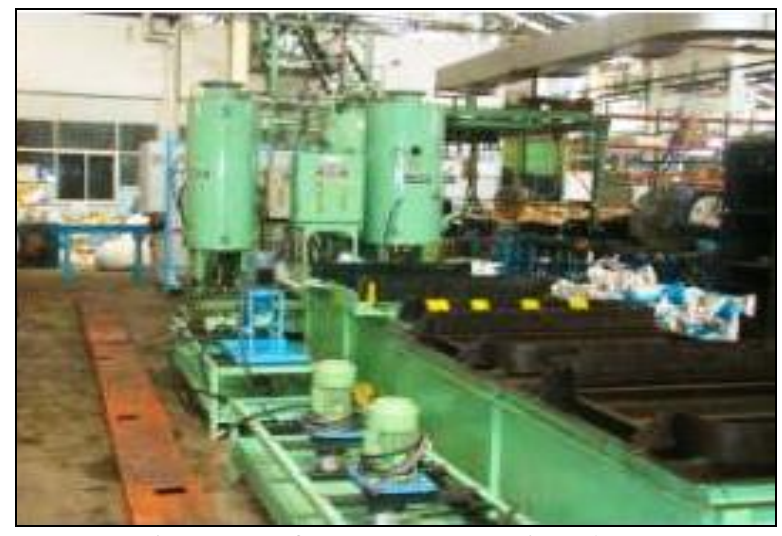

Fig.1.2 Safety Layout (Paint shop)

\section{IV .Training Methods: ergonomic perspective}

Training methods shall be chosen for teaching a particular topic/aspect of chemical disaster, from a range of following:

- Film show followed by question-answer, discussion

- Lecture followed by query-answers

- Presentation (slides) and discussion

- Group discussion

- Group work / assignment - exercise

- Field visit followed by discussion

- Mock exercise/ drills/

- Simulation, table-top

- Demonstration /Hands on exposure (Computer based)

- Panel discussion

\section{Training Module Training Materials and Facilities}

- Training hall / class room with suitable capacity and fixers

- Computers (for demonstration of GIS/ICT applications and modeling tools/ scenarios)

- LCD projector

- Screen

- Mike(s) and speaker(s)

- Flip chart,

- White board

- Computer stationary

- Folder, Pen, etc. Performance Aids

- Reading material - easy to understand and handle, containing reference literature about the course topics/contents

- Case Studies - printed versions

- Exercise Plan and Guidelines

- Copies of existing Off-site plans for evaluation/assessment

- Film on chemical disaster (for example, Bhopal tragedy)

- CD of Software - ALOHA, MARPLOT, AFFECTS, CAMEO, etc.

- Field visit arrangements - including safety helmets, field visit plan, etc.

- Handouts of Presentations: should be clear enough to read and with space for additional notes and writings must be provided

- Lecture notes: Some background information about the topics and themes of course lectures/case studies must be provided in the reading material. 


\section{Trainers/Learning Facilitators/Resource Persons}

A minimum team consisting three or more faculty members is required to organize (design, conduct and coordinate) the course. One of the team members must have some background of the specific state / region. The subject composition must encompass environment and earth science, disaster mitigation, environmental law, geoinformatics, information/communication technology, industrial chemistry / toxicology, emergency response, community preparedness for this suitable layout for training as shown in Fig1.3.

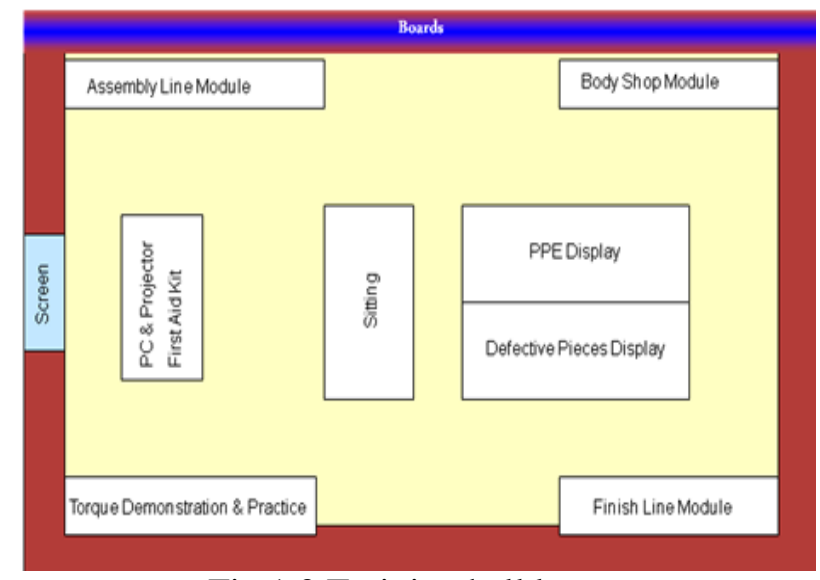

Fig.1.3 Training hall layout

\section{Field Visit}

A field visit to a MAH Unit or industrial area with hazardous units/operations is part of the suggested training module. It will provide real feel of the off- Chemical (Industrial) Disaster Management : Training Module site and on-site associated with the location of the unit, its hazard potential in terms of hazardous goods and processes, transport, etc. in the background of vulnerability of communities including their properties and environment, to realize the emergency response issues. Visit shall also be helpful in developing/improving understanding of the participants on aspects of impact assessment, site selection, housing, and emergency response planning and preparedness including routes, resources, locations, and coordination issues based on Hazard, risk, vulnerability and capacity (HRVC) rapid assessment [5].

\section{Disaster Plan}

This usually involves four phases:

1. Prevention

2. Preparedness

3. Response

4. Recovery

The following guide to producing a disaster plan outlines recommended action in all four phases, but prevention is the best protection against disaster, natural or man-made.

\section{Phase 1: Prevention}

Identify and minimize the risks posed by the building, its equipment and fittings, and the natural hazards of the area.

- Carry out a building inspection and alter factors which constitute a potential hazard.

- Establish routine housekeeping and maintenance measures to withstand disaster in buildings and surrounding areas.

- Install automatic fire detection and extinguishing systems, and water-sensing alarms.

- Take special precautions during unusual periods of increased risk, such as building renovation.

- Make special arrangements to ensure the safety of library or archival material when exhibited. 
- Provide security copies of vital records such as collection inventories, and store these off-site

- Protect computers and data through provision of uninterrupted power supply.

- Have comprehensive insurance for the library or archives, its contents, the cost of salvage operations, and potential replacement, re-binding and restoration of damaged materials. [4]

\section{Phase 2: Preparedness getting ready to cope}

- Develop a written preparedness, response and recovery plan.

- Keep the plan up-to-date, and test it.

- Keep together supplies and equipment required in a disaster and maintain them.

- Establish and train an in-house disaster response team. Training in:

> Disaster response techniques, - identification and marking on floor-plans and enclosures of irreplaceable and important material for priority salvage.

- Prepare and keep an up-to-date set of documentation including:

$>$ Building floor-plans, with locations of cut-off switches and valves. - Inventory of holdings, with priorities for salvage marked on floor-plans.

$>$ List of names, addresses, and home telephone numbers of personnel with emergency responsibilities.

> List of names, addresses, and home telephone numbers of the in-house disaster response team.

$>$ List of names, addresses and home telephone numbers of trained conservators with experience in salvaging water-damaged materials, resource organisations, and other facilities able to offer support in the event of a disaster.

$>$ List of disaster control services, in-house supplies and equipment, and in any central store, including locations and names of contacts with home telephone numbers.

$>$ List of suppliers of services and sources of additional equipment and supplies, including names of contacts and home telephone numbers.

$>$ Arrangements made to access freezing facilities.

$>$ Arrangements for funding emergency needs.

$>$ Copies of insurance policies.

$>$ Salvage procedures.

\section{Phase 3: Response when disaster strikes}

- Follow established emergency procedures for raising the alarm, evacuating personnel and making the disaster site safe

- Contact the leader of the disaster response team to direct and brief the trained salvage personnel

- When permission is given to re-enter the site, make a preliminary assessment of the extent of the damage, and the equipment, supplies and services required.

- Stabilize the environment to prevent the growth of mould.

- Medical response has to be fast and effective [3].

\section{Phase 4: Recovery getting back to normal}

- Establish a programme to restore both the disaster site and the damaged materials to a stable and usable condition.

- Determine priorities for restoration work and seek the advice of a conservator as to the best methods and options, and obtain cost estimates.

- Develop a phased conservation programme where large quantities of material are involved.

- Discard items not worth retaining, and replace or re-bind items not justifying special conservation treatment.

- Contact insurers.

- Clean and rehabilitate the disaster site.

- Replace treated material in the refurbished site. 
- Analyse the disaster and improve the plan in the light of experience. - Be prepared for any type of disaster. Contact and consult other libraries or archives and library or archives associations to share information and experience, and with a view to regional cooperation. - Take advantage of educational sessions, particularly disaster planning workshops and preparedness exercises. - Seek expert advice and help from the preservation offices of national and large research libraries, members of the Standing Committee of the Section on Conservation of the IFLA, the centres of the IFLA-PAC Programme, and the Technical Committees of ICA and of the International Audiovisual Archives Associations FIAF, FIAT, and IASA [6].

\section{Conclusion}

Less hazard layout and risk mapping is the first step towards the design of plan at the factory level, local level. Risk Assessment is simply a careful examination of whatever that could cause harmful to people, so that one can find what safety or controls are need to prevent harmful issues. Risk Assessment helps to future plan any unwanted risk, estimating harmful potential of such situation, effective decision making to control such issues and evaluating effectiveness of control measures towards safety. In order to prevent a harmful issues from becoming a disaster and to minimize the likely impacts on people life, machine, materials and environment. Paper shows that how to implement the disaster recovery plans and four elements of the disaster recovery plan: prevention, preparedness, response, and recovery.

\section{Acknowledgments}

We express our deep sense of gratitude to Mechanical and Civil Engineering Department of AGTI's DACOE, Karad. We acknowledge with thanks to faculty, teaching and non-teaching staff of the Mechanical and Civil engineering department, Central library and Colleagues. We would like to thanks the Emerson Climate Technologies, Atit for their cooperation.

\section{References}

[1] Holmes E. miller, Kurt J. Engelmann, Ronald R. Yager, "Disaster planning and management", communication of IIMA, 2006 volume 6, Issue2, pp.25-36.

[2] National disaster management authority of India, Government of India: www. ndma.gov.in/National policy_on_disaster_management.pdf

[3] Anil K. Gupta, Sreeja S.Nair ,National Institute of Disaster Management, Government of India.

[4] Narendra Kumar Tewari, "Chemical disaster management: current status and perspective", UPSDMA, Sept2015.

[5] Disaster Planning prevention, preparedness, response, recovery.pdf

[6] S.J. Hu , J. Ko, L. Weyand, H.A. E Maraghy, T.K. Lien, Y. Koren, H. Bley ,G. Chryssolouris , N. Nasr , M. Shpitalni , "Assembly system design and operations for product variety", CIRP Annals Manufacturing Technology 60 (2011), pp. 715-733.

[7] Alena Otto, Armin Scholl "Incorporating ergonomic risks into assembly line balancing ", European Journal of operation Research 212 (2011), pp. 277-286. 